\title{
Influence of Job Characteristics on Job Satisfaction - Mediation Effect of Job Ethics and Job Engagement
}

\author{
YoungMok Kim ${ }^{1}$, HeeJung Lee ${ }^{2}$, and Sela Lim $^{3 *}$ \\ 1,3*Department of Clinical Psychology, NungIn University, \\ Paltan-myeon, Hwaseong-si, Gyeonggi-do, Korea \\ ${ }^{2}$ Department of Naturopathic, Dongbang Culture University, \\ Seongbuk-gu, Seoul, Korea \\ 1ymkim3102@naver.com, ${ }^{2}$ anahjlee57@naver.com, ${ }^{3 *}$ sera325@nate.com
}

\begin{abstract}
This study explored the correlation of $K$ pharmaceutical company's Staff for job characteristics and job satisfaction to confirm the mediation model and path of job ethics and job engagement. To this end, data were collected from 366 survey results conducted by 370. The survey consisted of, the job characteristics scale and job satisfaction scale, job ethics scale, and job engagement scale. Bootstrapping methods were used by the author to verify the average and standard deviation of variables, and to create the mediation model of how job characteristics relate to job satisfaction, job ethics, and job engagement. To verify the average and standard deviation of variables and mediation model of how job characteristics to job satisfaction through, job ethics and job engagement the author used bootstrapping methods. For the research result, this study presented descriptive statics for each variable of respondents' and conducted correlation analysis among job characteristics to job satisfaction through job ethics and job engagement ( $\beta=.046$, C.I[.021 .075]). And job characteristics to job satisfaction through job ethics $(\beta=.000$, C.I[-.039 .042]). And job characteristics to job satisfaction through job engagement ( $\beta=.185$, C.I[.126 .249]) And job characteristics to job satisfaction $(\beta=.221$, C.I[.147 -.294]). Furthermore, the pathway model showed significant relationships among job characteristics, job satisfaction, job ethics, and job engagement. The mediation analysis revealed that there were meaningful correlations among job characteristics, job, job satisfaction, job ethics, and job engagement in pharmaceutical company's staff. 1
\end{abstract}

Keywords: Job, Characteristics, Satisfaction, Ethics, Engagement

\section{Introduction}

In the modern culture, job-related schemes have come under pressure from rising costs and increasing complexity. Examples of general job characteristics include work overload, role problems, deprived job control, lack of support from supervisors and coworkers, and interpersonal conflicts in cognitive (evaluative), affective (or emotional), and behavioral components. The job characteristics are closely related to job satisfaction [1]. In recent years, the importance of job effectiveness has been emphasized in South Korea due to the causes

Article history:

Received (June 15, 2020), Review Result (July 18, 2020), Accepted (August 25, 2020) 
and negative results of job ethics [2] to improve the productivity of the workplace for job engagement [3]. The results of a previous study also showed that office workers [4], which is an important variable related to Job characteristics, are a factor affecting the job ethics and satisfaction of people.

It is the bane of the modern world. These characteristics may lead to negative psychological (e.g., depression, irritability, and burnout), physical (e.g., headaches, heart palpations, and hyperventilation), and behavioral (e.g., absenteeism, turnover, and violence) symptoms or 'strain sensation'.

The psychological process that is involved in dealing with these job ethics to reduce strain is called a 'coping mechanism'. Coping mechanism with job satisfaction is a key concept in understanding people's adaptation to their job characteristics.

More specially, coping with job engagement refers to the mental and behavioral strategies that employees use to handle the satisfaction they encounter at work.

When job satisfaction becomes increasingly difficult to control, it often leads to job characteristics, job ethics, and job engagement. Therefore, we have to conceptualize the role of ethical leaders with the psychological intervention about the job model.

There seem to be two answers.

First, people work because they want to overcome psychological or cognitional problems: a job as a means for modification of job ethics.

Second, people work to achieve a better understanding of job engagement for their job life.

These two aims often cannot be separated, and most practitioners of the job probably pursue both to a certain extent. People who have undergone extensive job training for job characteristics and job satisfaction have shown improvements in cognitive performance in job ethics and job engagement.

Despite the public's growing interest and an increasing number of studies on the impact of job characteristics and job satisfaction, there is a surprising scarcity of summaries of the empirical evidence, especially for evidence that stems from research outside the therapeutic context within job ethics and job engagement.

Numerous studies have been conducted to search for the effects of fields of pharmaceutical company's Staff of study, yet there is an even more surprising lack of elaborate psychological theories that make sound predictions about what to expect if one works.

This theoretical approach is frequently mirrored in the measures used in the studies, which include all kinds of dependent variables that are not specific to work (job characteristics and job satisfaction) research and have also been used in many other kinds of research.

Although in this article, we place an emphasis on empirical evidence, we are convinced that real progress in understanding the effects of job characteristics and job satisfaction cannot be made if future empirical studies are not guided by better theories.

As a result, after momentarily surveying previous attempts to summarize the literature on the effects of job characteristics, job ethics, job engagement, and satisfaction, we introduce existing theoretical approaches from South Korea. Following our analysis of the empirical evidence, we return to the issue of how we might make progress in understanding job characteristics, job ethics, job engagement, and job satisfaction and its effects. Kim reported the results of a positive correlation between job ethics and job engagement [4]. In addition, comparative studies of research or cognition types focusing on psychological intervention have reported that psychological intervention positively affects victims' mental health as well as job characteristics and job satisfaction and, in some cases, has more positive and long-term effects than job ethics and job engagement. 
It would be useful for enhancing the understanding of the factors affecting the mediator and could provide the opportunity for the clinician to provide basic data on research and psychotherapy.

\section{Methods}

\subsection{Subjects and data collection}

This study was conducted from July 2019 to August 2019, for those who participated in the Male and Female in Seoul of Korea. Finally, the data of a total of 366 participants were analyzed.

\subsubsection{Subjects of gender}

The gender of the participants is as follows [Table 1]

Table 1. Subjects of gender $(\mathrm{N}=366)$

\begin{tabular}{|c|c|c|}
\hline & $\mathrm{N}$ & Percent \\
\hline Males & 305 & 83.3 \\
\hline Females & 61 & 16.7 \\
\hline Total & 366 & 100 \\
\hline
\end{tabular}

\subsubsection{Subjects of age}

The age of the participants is as follows [Table 2].

Table 2. Subjects of age $(\mathrm{N}=366)$

\begin{tabular}{|c|c|c|}
\hline Age & N & Percent \\
\hline $20-29$ & 36 & 9.8 \\
\hline $30-39$ & 204 & 55.7 \\
\hline $40-49$ & 114 & 31.1 \\
\hline $50-59$ & 11 & 3 \\
\hline $60-69$ & 1 & 0.3 \\
\hline Total & 366 & 100 \\
\hline
\end{tabular}

\subsubsection{Subjects of the variable of position annual income}

The annual incomes of the participants are as follows [Table 3].

Table 3. Subjects of annual income $(\mathrm{N}=366)$

\begin{tabular}{|c|c|c|}
\hline Sum & N & Percent \\
\hline Less than 25.000 & 35 & 9.6 \\
\hline Less than 42.000 & 126 & 34.4 \\
\hline Less than 50.000 & 112 & 30.6 \\
\hline
\end{tabular}




\begin{tabular}{|c|c|c|}
\hline Less than 58.000 & 69 & 18.9 \\
\hline Less than 75.000 & 17 & 4.6 \\
\hline More than $90.000 \$$ & 6 & 1.6 \\
\hline Missing Value & 1 & 0.3 \\
\hline Total & 366 & 100 \\
\hline
\end{tabular}

\subsubsection{Description of the variable of occupational group}

The description of the variable of an occupational group of the participants is as follows [Table 4].

Table 4. Description of the variable of the occupational group $(\mathrm{N}=366)$

\begin{tabular}{|c|c|c|c|c|c|c|c|c|c|}
\hline \multirow{2}{*}{ Task } & \multirow{2}{*}{$\mathrm{N}$} & \multicolumn{2}{|c|}{ Job characteristics } & \multicolumn{2}{c|}{ Job ethics } & \multicolumn{2}{c|}{ Job engagement } & \multicolumn{2}{c|}{ Job satisfaction } \\
\cline { 3 - 11 } & & $M$ & $S D$ & $M$ & $S D$ & $M$ & $S D$ & $M$ & $S D$ \\
\hline Salesman & 235 & 3.75 & 0.49 & 3.90 & 0.48 & 3.82 & 0.61 & 3.29 & 0.38 \\
\hline Managerial staff & 91 & 3.63 & 0.51 & 4.00 & 0.44 & 3.69 & 0.67 & 3.21 & 0.42 \\
\hline Research service & 12 & 3.83 & 0.57 & 3.79 & 0.44 & 4.12 & 0.48 & 3.43 & 0.33 \\
\hline Production worker & 18 & 3.48 & 0.56 & 3.93 & 0.40 & 3.75 & 0.47 & 3.17 & 0.61 \\
\hline Others & 10 & 3.30 & 0.41 & 3.73 & 0.34 & 3.44 & 0.38 & 3.24 & 0.31 \\
\hline Total & 366 & 3.70 & 0.51 & 3.92 & 0.46 & 3.78 & 0.61 & 3.27 & 0.40 \\
\hline
\end{tabular}

\subsubsection{Description of the variable of the work period}

The Description of the variable of work period of the participants is as follows [Table 5].

Table 5. Description of the variable of work period $(\mathrm{N}=366)$

\begin{tabular}{|c|c|c|c|c|c|c|c|c|c|}
\hline \multirow{2}{*}{ work period } & \multirow{2}{*}{$\mathrm{N}$} & \multicolumn{2}{|c|}{ Job characteristics } & \multicolumn{2}{|c|}{ Job ethics } & \multicolumn{2}{c|}{ Job engagement } & \multicolumn{2}{c|}{ Job satisfaction } \\
\cline { 3 - 11 } & $M$ & $S D$ & $M$ & $S D$ & $M$ & $S D$ & $M$ & $S D$ \\
\hline $\begin{array}{c}\text { Less than } \\
\text { 0-3years }\end{array}$ & 65 & 3.60 & 0.53 & 3.94 & 0.54 & 3.76 & 0.69 & 3.26 & 0.47 \\
\hline $\begin{array}{c}\text { Less than } \\
\text { 3-5years }\end{array}$ & 66 & 3.58 & 0.67 & 3.76 & 0.61 & 3.48 & 0.76 & 3.13 & 0.49 \\
\hline $\begin{array}{c}\text { Less than } \\
\text { 5-10years }\end{array}$ & 105 & 3.73 & 0.43 & 3.94 & 0.37 & 3.82 & 0.53 & 3.31 & 0.35 \\
\hline $\begin{array}{c}\text { Less than } \\
\text { 10-15years }\end{array}$ & 83 & 3.77 & 0.45 & 3.95 & 0.38 & 3.87 & 0.50 & 3.28 & 0.35 \\
\hline $\begin{array}{c}\text { Less than } \\
\text { 15-20years }\end{array}$ & 36 & 3.75 & 0.41 & 4.02 & 0.43 & 3.98 & 0.54 & 3.34 & 0.30 \\
\hline $\begin{array}{c}\text { Less than } \\
\text { 20-25years }\end{array}$ & 6 & 4.13 & 0.22 & 3.91 & 0.38 & 4.14 & 0.34 & 3.35 & 0.20 \\
\hline $\begin{array}{c}\text { Less than } \\
\text { 25-30years }\end{array}$ & 4 & 3.89 & 0.46 & 4.08 & 0.17 & 4.11 & 0.43 & 3.41 & 0.29 \\
\hline $\begin{array}{c}\text { More than } \\
\text { 30 years }\end{array}$ & 1 & 4.00 &. & 4.33 &. & 4.43 &. & 3.31 &. \\
\hline \begin{tabular}{c} 
Total \\
\hline
\end{tabular} & 366 & 3.70 & 0.51 & 3.92 & 0.46 & 3.78 & 0.61 & 3.27 & 0.40 \\
\hline
\end{tabular}




\subsection{Measurement}

(1) Job characteristics Questionnaire: To measure job characteristics, we used the Job Characteristics Questionnaire (JCQ) developed by Hackman and Oldham (1980) [5]. In the present study, Cronbach's $\alpha$ of job characteristics was .825 .

(2) Job satisfaction Questionnaire: To measure job satisfaction, we used the Job Satisfaction Questionnaire (JSQ), which was developed by Lee [6].

(3) Job ethics Questionnaire: To measure job ethics, we used the Job Ethics Questionnaire (JEQ), which was developed by Kang [7]. In the present study, the total of the job ethics of Cronbach's $\alpha$ was .830 .

(4) Job Engagement Questionnaire: To measure job engagement, we used the Job Engagement Questionnaire (JEQ), which was developed by Kanugo [8] which was adapted by Kim [9]. In the present study, the total job engagement of Cronbach's $\alpha$ was .924 .

\subsection{Data analysis}

Data collected for this study were analyzed using the IBM SPSS V.22 as follows. We used a $95 \%$ confidence interval based on the empirical distribution estimated by bootstrapping to verify the mediating effect. Bootstrapping interpreted the sample as statistically significant if it did not know the distribution of the population and if the $95 \%$ confidence interval did not include zero [10][11].

\section{Results}

\subsection{Correlation analysis}

The correlation analysis is as follows [Table 6].

Table 6. Correlation analysis

\begin{tabular}{|c|c|c|c|c|}
\hline & Job characteristics & Job ethics & Job engagement & Job satisfaction \\
\hline Job characteristics & 1 & & & \\
\hline Job ethics & $.482 * *$ & 1 & & \\
\hline Job engagement & $.573 * *$ & $.457 * *$ & 1 & \\
\hline Job satisfaction & $.572 * *$ & $.367 * *$ & $.670 * *$ & 1 \\
\hline$p<.05 * * p<0.01 * * * p<.001$ \\
F
\end{tabular}

\subsection{Path model}

A job characteristics analysis was conducted to confirm the effects of job satisfaction. Specifically, the job characteristics and job satisfaction have a significant effect on job ethics and engagement, in addition, the job characteristics were found to have a significant effect on job ethics $(\beta=.482, \mathrm{p}<.001)$, and the job characteristics were found to have a significant job engagement $(\beta=.460, p<.001)$, and the job characteristics was found to have a significant job satisfaction $(\beta=.280, p<.001)$. A significant correlation was found between job ethics and job engagement $(\beta=.236, p<.001)$. A significant correlation was not found between job ethics and job satisfaction $(\beta=.000, n . s)$, and the job engagement was found to have a significant job satisfaction $(\beta=.509, \mathrm{p}<.001)$. [Table 7]. 
Table 7. A Path model analysis of job characteristics and job satisfaction interval

\begin{tabular}{|c|c|c|c|c|c|c|c|}
\hline \multicolumn{3}{|c|}{ Path } & B & B & s.e & $\mathrm{t}$ & $\mathrm{p}$ \\
\hline \multirow{3}{*}{ Job characteristics } & \multirow{3}{*}{$\rightarrow$} & Job ethics & 0.441 & .482 & .042 & 10.488 & .000 \\
\hline & & Job engagement & 0.558 & .460 & .058 & 9.680 & .000 \\
\hline & & Job satisfaction & 0.226 & .280 & 0.37 & 5.890 & .000 \\
\hline \multirow{2}{*}{ Job ethics } & \multirow{2}{*}{$\rightarrow$} & Job engagement & 0.312 & .236 & .063 & 4.964 & .000 \\
\hline & & Job satisfaction & 0.000 & .000 & .038 & -0.004 & .997 \\
\hline Job engagement & $\rightarrow$ & Job & 0.331 & .509 & .030 & 10.871 & .000 \\
\hline
\end{tabular}

\subsection{Measurement model}

We performed bootstrapping by extracting 2000 parts of the job characteristics to the job stress through job ethics and job engagement.

As a result, the indirect effect was significant because the path through the job ethics and job engagement included 0 in the $95 \%$ confidence interval of the indirect effect $(\beta=.046$, C.I[.021 .075]).

And as a result, the indirect effect was significant because the path through the job ethics included 0 in the 95\% confidence interval of the indirect effect ( $\beta=.000$, C.I[-.039 .042]).

And as a result, the indirect effect was significant because the path through the job engagement included 0 in the $95 \%$ confidence interval of the indirect effect $(\beta=.185$, C.I[.126 .249]).

As a result, the indirect effect was significant because the path through the job characteristics and job satisfaction included 0 in the $95 \%$ confidence interval of the indirect effect ( $\beta=.221$, C.I[.147 -.294]) [Table 8].

Table 8. Measurement model of the mediator effect of job characteristics and job satisfaction interval

\begin{tabular}{|c|c|c|c|c|c|c|c|}
\hline $\begin{array}{c}\text { Independent } \\
\text { variable }\end{array}$ & Parameter & 1 Parameter2 & $\begin{array}{c}\text { Dependent } \\
\text { variable }\end{array}$ & \begin{tabular}{|c} 
Total effect \\
[bootstrappingC \\
$95 \%]$
\end{tabular} & $\begin{array}{c}\text { Direct } \\
\text { Ileffect[bootstrappingC } \\
95 \% \text { ] }\end{array}$ & $\begin{array}{c}\text { Total indirect } \\
\text { Ileffect[bootstrappingC } \\
95 \%]\end{array}$ & \begin{tabular}{|c|} 
Indirect \\
Ileffect[bootstrappingCI \\
$95 \%]$
\end{tabular} \\
\hline $\begin{array}{c}\text { Job } \\
\text { characteristics }\end{array}$ & Job ethics & $\begin{array}{c}\text { Job } \\
\text { engagement }\end{array}$ & $\begin{array}{c}\text { Job satis } \\
\text { faction }\end{array}$ & \multirow{4}{*}{$\begin{array}{c}.451[.384 \sim- \\
.518]\end{array}$} & \multirow{3}{*}{-} & \multirow{3}{*}{$.230[.163 \sim .302]$} & $.046[.021 \sim .075]$ \\
\hline $\begin{array}{c}\text { Job } \\
\text { characteristics }\end{array}$ & Job ethics & - & $\begin{array}{c}\text { Job } \\
\text { satisfaction }\end{array}$ & & & & $.000[-.039 \sim .042]$ \\
\hline $\begin{array}{c}\text { Job } \\
\text { characteristics }\end{array}$ & 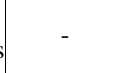 & $\begin{array}{c}\text { Job } \\
\text { engagement }\end{array}$ & $\begin{array}{c}\text { Job satis } \\
\text { faction }\end{array}$ & & & & $.185[.126 \sim .249]$ \\
\hline $\begin{array}{c}\text { Job } \\
\text { characteristics }\end{array}$ & & - & $\begin{array}{c}\text { Job satis } \\
\text { faction }\end{array}$ & & $.221[.147 \sim .294]$ & - & - \\
\hline
\end{tabular}

\section{Conclusions}

The results of this study suggest that the job characteristics of K pharmaceutical company's Staff have a significant effect on job satisfaction through job ethics and job engagement.

Meanwhile, a simple correlation analysis, revealed that there was a significant correlation between job characteristics, job ethics, job engagement, and job satisfaction, whereas the path search for the median model analysis was significant.

This is consistent with a previous study, which reported a significant correlation between job characteristics, of people and job satisfaction [12]. 
Lee [13] discovered that most causes of job characteristics that interfere with job ethics are experienced in work life.

Kim [14] discovered among work experienced people that most of the causes of job characteristics that interfere with thinking are related to job engagement, individual cognitional healthy work style, and experiences of job satisfaction in citizenship behavior.

Meynhardt, Brieger, and Hermann [15] discovered the influence of organizational common good practices in the perceptions of employees (measured as public value) on employees' work attitudes and life satisfaction.

Therefore, objective perception of changes in these cognition conditions could lead to a deterioration of psychological function.

In conclusion, the mediating effect of job characteristics, on job satisfaction and the job ethics and job engagement of pharmaceutical company Staff was solely analyzed in South Korea, and significant results were obtained. Nevertheless, it is important to note that results from this study could be used about cognitional work style especially during counseling interventions and in clinical settings.

\section{References}

[1] R. J. Hackman and G. R, Oldham, "Work redesign,” Addison-Wesley, Florida, pp.56, (1980)

[2] S. H. Yoon, "The effects of organizational managerial characteristics and job characteristics on job stress and job effectiveness: a survey on clinical nurses," Korean Journal of Psychology: Industrial and Organizational Psychology, vol.17, no.3, pp, 451-466, (2004)

[3] K. H. Roberts and W. Glick, "The job characteristics approach to task design: a critical review," Journal of Applied Psychology, vol.66, no.2, pp.193-217, (1981)

[4] J. H. Kim, "A study on factors influencing public service ethics of government officials," Ph.D. dissertation, Department of Public Administration, Graduate School of Konkuk University, (2013)

[5] J. R. Hackman, "Groups that work: Creating conditions for effective teamwork," Jossey-Bass, San Francisco, pp.126, (1980)

[6] K. H. Lee. "An effect of the job characteristics and organization culture on the job satisfaction," M.S. thesis, The Graduate School of Kyung Hee of Management MBA, Kyung Hee University, (2015)

[7] S. W. Kang, "A study on social factors influencing ethics in bureaucrats," Ph.D. dissertation, Department of Public Administration, The Graduate School, Dongyang University, (2017)

[8] R. N. Kanungo, "Work alienation and involvement: problems and prospects," Applied Psychology, vol.30, no.1, pp.1-15, (1981) DOI:10.1111/j.1464-0597.1981.tb00976.x

[9] S. H. Kim, "A study on the effectiveness of job ability of aesthetician in national competency standard-based education," Ph.D. dissertation, Department of Art and Craft, Graduate School of Konkuk University, (2018)

[10] A. F. Hayes, "Introduction to mediation, moderation, and conditional process analysis: a regression-based approach," The Guilford Publications, New York, pp.169, (2017)

[11] P. E. Shrout and N. Bolger, "Mediation in experimental and nonexperimental studies: New procedures and recommendations," Psychological Methods, vol.7, no.4, pp.422, (2002)

[12] G. O. Lee, "The effects of job characteristics on the job stress and job satisfaction: in case of Inflight attendants," M.S. thesis, The Graduate School of Business Administration, Korea Aerospace University, (2009)

[13] J. S. Lee, "A study on the enhancement of public officials' public service ethics consciousness," M.S. thesis, Department of Public Administration, The Graduate School of Public Administration, Chung-Ang University, (2011)

[14] K. K. Kim, "Influences of hotel employee's job characteristic on organization commitment and job satisfaction and organizational citizenship behavior in the hotel corporation," vol.19, no.2, pp.469-488, (2006) 
Influence of Job Characteristics on Job Satisfaction - Mediation Effect of Job Ethics and Job Engagement

[15] T. Meynhardt, S. A. Brieger, and C. Hermann, "Organizational public value and employee life satisfaction: The mediating roles of work engagement and organizational citizenship behavior," The International Journal of Human Resource Management, vol.31, no.12, pp.1560-1593, (2020) 